\title{
PENGEMBANGAN MEDIA PEMBELAJARAN BERBASIS MULTIMEDIA INTERAKTIF AUTOPLAY DALAM MATERI MENERAPKAN ELEKTRONIKA DASAR PADA MATA PELAJARAN SISTEM KOMPUTER DI SMK NEGERI 1 TEJAKULA
}

\author{
I M. Resa Krisnayudha ${ }^{1}$, A. Adiarta ${ }^{2}$, N. Santiyadnya ${ }^{3}$ \\ 1,2,3Prodi Pendidikan Teknik Elektro, Universitas Pendidikan Ganesha, Singaraja \\ e-mail:maderesa070@gmail.com, agus.adiarta@undiksha.ac.id, santiyadnya@undiksha.ac.id
}

\begin{abstract}
Abstrak
Penelitian ini bertujuan 1) membuat media pembelajaran berbasis multimedia interaktif autoplay dalam materi menerapkan elektronika dasar pada mata pelajaran sistem komputer di SMK Negeri 1 Tejakula, 2) untuk mengetahui tingkat kelayakan terhadap media Pembelajaran Berbasis Multimedia Interaktif Autoplay dalam materi Menerapkan Elektronika Dasar pada Mata Pelajaran Sistem Komputer di SMK Negeri 1 Tejakula, 3) untuk mengetahui respon siswa terhadap Media Pembelajaran Berbasis Multimedia Interaktif Autoplay dalam materi Menerapkan Elektronika Dasar pada Mata Pelajaran Sistem Komputer di SMK Negeri 1 Tejakula. Penelitian ini menggunakan metode penelitian dan pengembangan atau lebih dikenal dengan Research and Development. Berdasarkan hasil penelitian yang telah dilaksanakan, diperoleh beberapa hasil yaitu: (1) hasil akhir dari media pembelajaran berbasis multimedia interaktif autoplay dalam materi menerapkan elektronika dasar pada mata pelajaran sistem komputer di SMK Negeri 1 Tejakula berupa CD interaktif, (2) hasil dari uji ahli mendapatkan hasil persentase untuk ahli materi $86,15 \%$ pada kualifikasi sangat layak dan, hasil persentase untuk ahli media $97,78 \%$ kualifikasi sangat layak, (3) respons siswa mendapatkan hasil persentase untuk uji kelompok kecil $87,47 \%$ pada kualifikasi sangat baik, dan hasil persentase uji kelompok besar $88,11 \%$ pada kualifikasi sangat baik. Berdasarkan hasil yang didapatkan, maka Media Pembelajaran Berbasis Multimedia Interaktif Autoplay dalam Materi Menerapkan Elektronika Dasar pada Mata Pelajaran Sistem Komputer di SMK Negeri 1 Tejakuka, layak digunakan sebagai media pembelajaran.
\end{abstract}

Kata kunci: Media pembelajaran, multimedia interaktif autoplay, menerapkan elektronika dasar

\begin{abstract}
This study aims to 1) create a media-based learning interactive multimedia autoplay in the material applying basic electronics on the subjects of computer systems in SMK Negeri 1 Tejakula, 2) to assess the feasibility of the medium-Based Learning Interactive Multimedia Autoplay in the material Applying Basic Electronics in Subjects System computers in SMK Negeri 1 Tejakula, 3) to determine the students' response to the Interactive Multimedia Learning Media Based Autoplay in Basic Electronics Applying material on the Subject computer Systems at SMK Negeri 1 Tejakula. This study uses research and development, or better known as the Research and Development. Based on the research that has been conducted, we obtain some results, namely: (1) the outcome of interactive multimedia-based learning media autoplay in applying basic electronic material on the subjects of computer systems in SMK 1 Tejakula form of interactive $C D$, (2) the results of the expert test to get the percentage of material experts $86.15 \%$ on qualifying very decent and, the percentage of $97.78 \%$ for qualified media experts is very feasible, (3) in response to the percentage of students getting a small group of test $87.47 \%$ on excellent qualifications, and the percentage of $88.11 \%$ test a large group in qualifying very good. Based on the results obtained, the Interactive Multimedia Learning Media Based Autoplay in Basic Electronics Materials Applying the Lesson of Computer Systems at SMK Negeri 1 Tejakuka, fit for use as a medium of learning.
\end{abstract}

Keywords: Media learning, interactive multimedia autoplay, apply basic electronics 


\section{Pendahuluan}

Pendidikan merupakan salah satu komponen penting dalam kehidupan ini. Maju atau tidaknya sumber daya manusia ditentukan oleh pendidikan yang diterimanya. Menurut Kamus Besar Bahasa Indonesia (KBBI), pendidikan adalah suatu proses untuk mengubah sikap dan tingkah laku seseorang maupun kelompok orang dengan tujuan untuk mendewasakan seseorang melalui usaha pengajaran dan pelatihan.

Pendidikan dapat diperoleh di mana saja, kapan saja, dan untuk siapa saja baik secara formal maupun nonformal. Untuk mewujudkan hal itu, upaya yang dilakukan pemerintah dalam meningkatkan mutu pendidikan bagi Bangsa Indonesia adalah diterbitkannya UndangUndang Nomor 20 Tahun 2003 tentang sistem pendidikan nasional. Dalam pasal 3 dijelaskan bahwa pendidikan nasional berfungsi untuk (1) meningkatkan kemampuan dan membentuk watak serta peradaban bangsa yang bermatabat dalam rangka mencerdaskan kehid upan bangsa, (2) menjadikan manusia beriman dan bertaqwa kepada Tuhan Yang Maha Esa, (3) menumbuhkan ahlak mulia yang berilmu, cakap, kreatif, dan mandiri, serta (4) menjadikan warga Negara yang demokratis dan bertanggung jawab. Berdasarkan uraian tersebut, dapat dikatakan bahwa untuk mencapai tujuan pendidikan maka pendidikan merupakan hal yang wajib dimiliki oleh setiap orang dalam meningkatkan kualitas pendidikan.

Sekolah Menengah Kejuruan (SMK) merupakan salah satu lembaga pendidikan kejuruan yang mempunyai tugas untuk mempersiapkan peserta didiknya setelah lulus agar dapat bekerja langsung sesuai bidang-bidang tertentu sesuai jurusan yang dipilih. Dalam proses pembelajarannya, SMK dilengkapi dengan ilmu teori dan juga peserta didik dibekali keterampilan melalui praktek.

Keberhasilan proses pembelajaran merupakan seluruh aktivitas yang dilakukan guru dan siswa. Artinya apapun bentuk kegiatan-kegiatan guru, mulai dari merancang pembelajaran, memilih dan menentukan materi, pendekatan, strategi dan metode pembelajaran, memilih dan menentukan teknik evaluasi, semuanya diarahkan untuk mencapai keberhasilan siswa. Meskipun guru secara bersungguh-sungguh telah berupaya merancang dan melaksanakan kegiatan pembelajaran dengan baik, namun masalah-masalah belajar tetap akan dijumpai oleh guru.

Salah satu cara untuk mencapai keberhasilan dalam pembelajaran adalah dengan adanya media pembelajaran bagi siswa. Untuk mencapai tujuan pembelajaran yang optimal sangatlah perlu menggunakan media sebagai alat bantu dalam proses pembelajaran. Media pembelajaran merupakan salah satu komponen pembelajaran yang mempunyai peranan penting dalam proses pembelajaran. Pemanfaatan media seharusnya menjadi hal yang mendapat perhatian guru sebagai fasilitator dalam setiap kegiatan pembelajaran. Oleh karena itu, tiap-tiap guru perlu mempelajari bagaimana menetapkan media pembelajaran agardapat mengefektifkan pencapaian tujuan pembelajaran dalam proses belajar mengajar. Media pembelajaran secara umum merupakan alat bantu proses belajar mengajar yang dapat dipergunakan untuk merangsang pikiran, perasaan, perhatian dan kemampuan atau ketrampilan pebelajar sehingga dapat mendorong terjadinya proses belajar.

SMK Negeri 1 Tejakula merupakan salah satu sekolah menengah kejuruan yang memiliki mata pelajaran sistem komputer dengan materi menerapkan elektronika dasar yang juga menerapkan media pembelajaran dalam proses belajar di kelas. Berdasarkan hasil wawancara dengan guru dan hasil observasi yang dilakukan di kelas $X$ TKJ pada materi menerapkan elektronika dasar terdapat permasalahan antara lain: (1) guru hanya menggunakan metode ceramah dalam proses penyampaian materi di kelas, (2) dalam proses penyampaian pelajaran menerapkan elektronika dasar pada mata pelajaran sistemkomputer di kelas, guru hanya menggunakan media power point, (3) pemahaman siswa tentang materi menerapkan elektronika dasar belum maksimal, (4) semangat siswa belum maksimal dalam proses belajar di kelas, (5) siswa kurang tertarik saat guru menyampaikan materi di kelas, (6) kemampuan siswa tidak sesuai dengan harapan guru, dilihat dari hasil ulangan harian menunjukkan sebagian besar siswa remidi dan, (7) variasi media pembelajaran yang digunakan dalam penyampaian materi belum maksimal diantaranya belum tersedianya media 
pembelajaran berbasis multimedia interaktif autoplay dalam materi menerapkan elektronika dasar pada mata pelajaran sistem komputer di SMK Negeri 1 Tejakula.

Berdasarkan uraian latar belakang tersebut, dikembangkan media pembelajaran berbasis multimedia interaktif autoplay dalam materi menerapkan elektronika dasar pada mata pelajaran sistem komputer di SMK Negeri 1 Tejakula. Media pembelajaran ini diharapkan dapat membantu guru dan siswa dalam penyampaian materi di kelas ataupun sebagai bahan belajar siswa di luar kelas.

Berdasarkan uraian latar belakang yang telah dikemukakan diatas, dapat dirumuskan permasalahan sebagai berikut. (1) Bagaimanakah desain produk media pembelajaran berbasis multimedia interaktif autoplay dalam materi menerapkan elektronika dasar pada mata pelajaran sistem komputer di SMK Negeri 1 Tejakula? (2) Apakah media pembelajaran berbasis multimedia interaktif autoplay layak digunakan dalam materi menerapkan elektronika dasar pada mata pelajaran sistem komputer di SMK Negeri 1 Tejakula? (3) Bagaimanakah respons siswa terhadap media pembelajaran berbasis multimedia interaktif autoplay dalam materi menerapkan elektronika dasar pada mata pelajaran sistem komputer di SMK Negeri 1 Tejakula?.

Sesuai Sesuai dengan latar belakang dan rumusan masalah yang telah dipaparkan diatas, maka tujuan dari pengembangan adalah sebagai berikut. (1) Untuk membuat media pembelajaran berbasis multimedia interaktif autoplay dalam materi menerapkan elektronika dasar pada mata pelajaran sistem komputer di SMK Negeri 1 Tejakula. (2) Untuk mengetahui tingkat kelayakan media pembelajaran berbasis multimedia interaktif autoplay dalam materi menerapkan elektronika dasar pada mata pelajaran sistem komputer di SMK Negeri 1 Tejakula. (3) Untuk mengetahui respons siswa terhadap media pembelajaran berbasis multimedia interaktif autoplay dalam materi menerapkan elektronika dasar pada mata pelajaran sistem komputer di SMK Negeri 1 Tejakula.

\section{Metode}

Berdasarkan rumusan masalah dan tujuan penelitian yang telah di paparkan dengan judul peneliatian Pengembangan Media Pembelajaran Berbasis Multimedia Interaktif Autoplay Dalam Materi Menerapkan Elektronika Dasar Pada Mata Pelajaran Sistem Komputer Di SMK Negeri 1 Tejakula. Metode penelitian yang akan digunakan adalah penelitian dan pengembangan (Research and Development). Penelitian dan pengembangan adalah metode penelitian yang digunakan untuk menghasilkan produk tertentu dan menguji keefektifan produk tertentu (Sugiyono, 2015: 407). Terdapat 10 langkah penggunaan model penelitian Research and Development (R\&D) yaitu (1) potensi dan masalah, (2) pengumpulan data, (3) desain produk, (4) validasi desain, (5) revisi desain, (6) uji coba produk, (7) revisi produk, (8) uji coba pemakaian, (9) revisi produk dan, (10) produksi massal.

Dalam penelitian ini instrumen yang digunakan adalah 1) lembar validasi media untuk mengetahui kualitas media yang dihasilkan, sehingga layak diujicobakan, 2) lembar validasi materi yang digunakan untuk mengetahui seberapa lengkap materi yang terdapat pada media tersebut, 3) lembar angket atau kuisioner respons siswa untuk mengetahui tanggapan siswa terhadap media pembelajaran yang dihasilkan. Angket ini akan diberikankepada siswa kelas X TKJ untuk mengukur kelayakan dari media pembelajaran yang dihasilkan. Pada angket ini, untuk mengukur kelayakan alat, peneliti menggunakan skala Linkert, dimana variabel yang akan diukur dijabarkan menjadi indikator variabel, kemudian indikator tersebut dijadikan itemitem pertanyaan atau pernyataan (Sugiyono dalam Dewi, 2018: 35).

Instrumen penelitian adalah alat yang digunakan untuk mengumpulkan data penelitian dengan cara melakukan pengukuran. Menurut Sugiyono (dalam Dewi, 2018: 34) "Instrumen penelitian adalah suatu alat yang digunakan untuk mengukur fenomena alat atau sosialyang diamati”. Menurut Suharsimi Arikunto (dalam Dewi, 2018: 43), instrumen penelitian adalah alat atau fasilitas yang digunakan oleh peneliti dalam mengumpulkan data agar pekerjaannya lebih mudah, dan hasilnya lebih baik, dalam arti lebih cermat, lengkap dan sistematis sehingga lebih mudah diolah. 
Dalam penelitian ini teknik analisa data menggunakan statistik deskriptif persentase dan jenis data yang digunakan adalah data kuantitatif. Statistik deskriptif adalah statistik yang digunakan untuk menganalisis data dengan cara mendeskripsikan atau menggambarkan data yang terkumpul sebagaimana adanya tanpa bermaksud membuat kesimpulan yang berlaku untuk umum atau generalisasi (Sugiyono dalam, Dewi 2018: 36).

Data penelitian kuantitatif diperoleh berupa angka-angka yang akan diolah menggunakan rumus statistik yang kemudian dihitung secara manual atau menggunakan alat komputer. Dalam penelitian ini, data didapat dari instrumen yang diisi oleh validasi dan instrumen angket siswa yang diisi oleh siswa. Lembar validasi yang pertama adalah lembar validasi media yg diisi oleh ahli media (dosen), yang kedua adalah lembar validasi isi yang diisi oleh ahli isi (guru mata pelajaran), dan yang ketiga adalah lembar angket siswa yang diisi oleh siswa.

Dalam analisis data oleh penilai, penilaian berupa sangat setuju, setuju, kurang setuju, tidak setuju, sangat tidak setuju, dari setiap jawaban memiliki gradasi ditunjukan pada Tabel 1 dan Tabel 2.

Tabel 1

Kriteria Penilaian Validator

\begin{tabular}{ccc}
\hline Kriteria & Jawaban & Skor \\
\hline Sangat Setuju & SS & 5 \\
Setuju & S & 4 \\
Kurang Setuju & KS & 3 \\
Tidak Setuju & TS & 2 \\
Sangat Tidak Setuju & STS & 1 \\
\hline
\end{tabular}

Tabel 2

Kualifikasi tingkat kelayakan berdasarkan presentase

\begin{tabular}{ccc}
\hline No & Interval $(\%)$ & Kriteria \\
\hline 1 & $84,01-100$ & Sangat Layak \\
2 & $68,01-84,00$ & Layak \\
3 & $52,01-68,00$ & Cukup Layak \\
3 & $36,01-52,00$ & Kurang Layak \\
4 & $20,00-36,00$ & Tidak Layak \\
\hline
\end{tabular}


Tabel 3

Kualifikasi tingkat respons siswa berdasarkan persentase

\begin{tabular}{ccc}
\hline No & Interval (\%) & Kualifikasi \\
\hline 1 & $84,01 \%-100 \%$ & Sangat baik \\
2 & $68,01 \%-84,00 \%$ & Baik \\
3 & $52,01 \%-68,00 \%$ & Cukup \\
3 & $36,01 \%-52,00 \%$ & Kurang \\
4 & $20,00 \%-36,00 \%$ & Sangat Kurang \\
\hline
\end{tabular}

\section{Hasil dan Pembahasan}

Pengembangan media pembelajaran menerapkan elektronika dasar dilaksanakan dalam dua tahapan. Tahap pertama melakukan uji validasi terhadap media yang diuji oleh ahli media dan ahli materi. Ahli media dari media pembelajaran menerapkan elektronika dasar diuji oleh dosen yaitu Dr. I Made Tegeh, S.Pd., M.Pd., sedangkan untuk uji materi diuji oleh guru mata pelajaran sistem komputer yang mengajar di kelas X yaitu Bapak Gede Wertana Mahardika, S.Pd. Tahap kedua yaitu melakukan uji produk media pada siswa kelas X TKJ di SMK Negeri 1 Tejakula. Penelitian yang dilakukan adalah penelitian dan pengembangan media pembelajaran berbasis multimedia interaktif autoplay dalam materi menerapkan elektronika dasar pada mata pelajaran sistem komputer, yang bertujuan untuk mengetahui respons guru dan siswa serta untuk mengetahui kelayakan dari media pembelajaran berbasis multimedia interaktif autoplay dalam materi menerapkan elektronika dasar pada mata pelajaran sistem komputer di SMK Negeri 1 Tejakula.

Untuk penelitian tahap pertama dilakukan beberapa kegiatan diantaranya: (1) potensi dan masalah (2) pengumpuilan data, (3) desain produk, (4) validasi desain, dan (5) revisi desain. Tahap ini merupakan tahap dimana dilakukan pengujian terhadap tingkat kelayakan Media Pembelajaran Berbasis Multimedia Interaktif Autoplay dalam Materi Menerapkan Elektronika Dasar pada Mata Pelajaran Sistem Komputer di SMK Negeri 1 Tejakula yang dilakukan dengan uji kelayakan validasi media dan materi/isi. Skor validasi media dan materi berupa angket yang diperoleh dari dosen dan guru yang mengajar mata pelajaran sistem komputer materi menerapkan elektronika dasar yang dianggap sebagai ahli media dan ahli isi/materi. Uji ahli pertama merupakan uji media pembelajaran yang diserahkan pada Bapak Dr. I Made Tegeh, S.Pd., M.Pd.

Uji ahli kedua merupakan uji validasi materi/isi yang di isi oleh guru mata pelajaran sistem komputer jurusan TKJ yaitu Bapak Gede Wertana Mahardika, S.Pd. Penelitian tahap II ini merupakan penelitian yang di laksanakan setelah penelitian tahap I telah dilaksanakan dimana pada penelitian tahap II ini melakukan beberapa uji coba diantaranya: uji coba kelompok kecil dan uji coba kelompok besar.

Pada penelitian tahap II dilakukan 1) uji coba kelompok kecil terlebih dahulu dengan siswa sebanyak 5 orang dengan mewakili karakteristik populasi sasaran. Dari hasil uji kelompok kecil dengan aspek penilaian sebanyak 15 butir dan skor maksimal 75 poin. Dari hasil uji diambil 5 orang siswa secara acak untuk mecari persentase kelayakan. 2) Uji coba kelompok besar, penilaian uji kelayakan dilakukan pada pengguna yaitu siswa. Siswa yang memberikan penilaian yaitu seluruh siswa kelas X TKJ 1 SMK Negeri 1 Tejakula yang pernah melewati/mendapatkan sub materi menerapkan elektronika dasar mata pelajaran sistem komputer. Jumlah dari siswa adalah sebanyak 36 orang. Hasil papat dilihat pada tabel 4 . 
Tabel 4. Hasil

\begin{tabular}{cccc}
\hline Uji & Total poin & $\%$ & Kreteria \\
\hline Uji Media & 80 & $97,78 \%$ & Sangat layak \\
Uji Materi & 56 & $86,15 \%$ & Sangat layak \\
Uji Kelompok kecil & 328 & $87,47 \%$ & Sangat baik \\
Uji Kelompok Besar & 2.379 & $88,11 \%$ & Sangat baik \\
\hline
\end{tabular}

Penelitian ini merupakan penelitian yang dilakukan untuk mengetahui apakah Media Pembelajaran Berbasis Multimedia Interaktif Autoplay dalam Meteri Menerapkan Elektronika Dasar pada Mata Pelajaran Sistem Komputer Di SMK Negeri 1 Tejakula layak digunakan sebagai media pembantu dalam proses pembelajaran, serta untuk mengetahui bagaimana respon siswa.

Pembahasan pada penelitian ini ditunjukkan pada kesesuaian antara tujuan penelitian dengan hasil yang didapatkan. Adapun tujuan penelitian ini yaitu 1) untuk membuat media pembelajaran berbasis multimedia interaktif autoplay dalam materi menerapkan elektronika dasar pada mata pelajaran sistem komputer di SMK Negeri 1 Tejakula, 2) untuk mengetahui tingkat kelayakan media pembelajaran berbasis multimedia interaktif autoplay dalam materi menerapkan elektronika dasar pada mata pelajaran sistem komputer di SMK Negeri 1 Tejakula, 3) untuk mengetahui respons siswa terhadap media pembelajaran berbasis multimedia interaktif autoplay dalam materi menerapkan elektronika dasar pada mata pelajaran sistem komputer di SMK Negeri 1 Tejakula.

Hasil penelitian menunjukan bahwa media pembelajaran berbasis multimedia interaktif autoplay dalam meteri menerapkan elektronika dasar pada mata pelajaran sistem komputer di SMK Negeri 1 Tejakula dapat digunakan sebagai media pembelajaran untuk kelas X TKJ dalam materi menerapkan elektronika dasar. Dalam validasi desain yang menggunakan instrumen dengan skala Linkert untuk mendapatkan jawaban yang lebih nyata tentang pendapat atau sikap responden. Instrument tersebut untuk menguji kelayakan media dalam aspek materi/isi, desain, kemanfaatan, bahasa, dan pengoperasain pada mata pelajaran sistem komputer dalam materi menerapkan elektronika dasar. Untuk uji materi pada media pembelajaran yang dikembangkan, pengujian dilakukan oleh guru mata pelajaran sistem komputer di SMK Negeri 1 Tejakula.

Hasil uji tingkat kelayakan dari media dan materi, mendapatkan persentase $86,15 \%$ (sangat layak) untuk materi dari validator yaitu guru mata pelajaran sistem komputer dan untuk persentase kelayakan dari uji media yang diuji oleh dosen ahli media yaitu 97,78\% (sangat layak) maka hasil validasi dari desain Media Pembelajaran Berbasis Multimedia Interaktif Autoplay dalam materi Menerapkan Elektronika Dasar pada Mata Pelajaran Sistem Komputer di SMK Negeri 1 Tejakula dapat dinyatakan dalam kategori sangat layak dan dapat digunakan untuk proses penelitian lebih lanjut. Setelah melakukan uji media dan materi oleh ahli materi dan media, tahap selanjutnya yaitu uji coba produk yaitu uji kelompok kecil dan uji kelompok besar.

Media pembelajaran yang dikembangkan tersebut mendapatkan respons yang sangat baik dari siswa yang dapat dilihat pada hasil persentase rata-rata kelompok kecil sebesar $87,47 \%$ dan kelompok besar $88,11 \%$. Nilai tersebut masuk dalam kategori sangat baik yang dapat dilihat pada Tabel 3.6, sehingga media pembelajaran sudah dapat dimanfaatkan sebagai media pembelajaran dalam kegiatan belajar mengajar.

Dari pembahasan di atas, jika dibandingkan dengan hasil penelitian lainnya yang serupa yaitu pada Media Pembelajaran Microsoft Excel Berbasis Multimedia oleh Agus Buchori yang 
mana hasil yang diperoleh dari ahli media yaitu $70 \%$, dan ahli materi sebesar $81,25 \%$ lebih kecil dari presentase nilai yang diperoleh peneliti yaitu dari ahli media memporeleh hasil $97,78 \%$ dan untuk ahli materi memperoleh hasil $86,15 \%$. Kemudian persentase nilai dari respons siswa, penelitian yang dilakukan oleh Agus Buchori mendapatkan hasil $83,56 \%$ lebih kecil dari nilai yang diperoleh peneliti yaitu $88,11 \%$.

Meskipun memiliki perbedaan nilai dari penelitian yang lain, baik lebih rendah maupun lebih tinggi, penelitiaan yang dikembangkan oleh peneliti sudah sesuai dengan hipotesis peneliti. Maka media pembelajaran yang dikembangkan peneliti dikatakan Sangat Layak untuk dijadikan Media Pembelajaran di SMK Negeri 1 Tejakula.

\section{Simpulan dan Saran}

Dari hasil dan pembahasan yang telah dipaparkan dapat disimpulkan bahwa, hasil akhir dari Media Pembelajaran Berbasis Multimedia Interaktif Autoplay dalam Materi Menerapkan Elektronika Dasar pada Mata Pelajaran Sistem Komputer di SMK Negeri 1 Tejakula berupa CD interaktif, Media Pembelajaran Berbasis Multimedia Interaktif Autoplay dalam Meteri Menerapkan Elektronika Dasar layak digunakan pada Mata Pelajaran Sistem Komputer di SMK Negeri 1 Tejakula serta dapat digunakan untuk membantu proses pembelajaran dan mendapat respons baik dari siswa. Hasil uji validasi oleh ahli media yaitu mendapatkan persentase $97,78 \%$ (sangat layak), persentase ahli materi yaitu $86,15 \%$ (sangat layak), uji coba kelompok kecil di peroleh hasil rerata persentase $87,47 \%$ (kualifikasi sangat baik), dan uji coba kelompok besar di peroleh hasil rerata persentase $88,11 \%$ (kualifikasi sangat baik).

Adapun saran yang di sampaikan yang berkaitan dengan penelitian pengembangan media pembelajaran berbasis multimedia interaktif autoplay dalam meteri menerapkan elektronika dasar pada mata pelajaran sistem komputer yaitu sebagai berikut. (1) Kepada siswa, saran untuk siswa adalah agar menggunakan media pembelajaran berbasis multimedia interaktif autoplay dalam meteri menerapkan elektronika dasar pada mata pelajaran sistem komputer sebagai media pendukung dalam pembelajaran. (2) Kepada guru, saran bagi guru adalah media pembelajaran berbasis multimedia interaktif autoplay dalam meteri menerapkan elektronika dasar pada mata pelajaran sistem komputer agar diterapkan lebih lanjut dalam proses pembelajaran di kelas sehingga dapat mencapai tujuan pembelajaran efektif dan efisien. (3) Kepada kepala sekolah, saran bagi kelapa sekolah adalah mengelola media pembelajaran berbasis multimedia interaktif autoplay dalam meteri menerapkan elektronika dasar pada mata pelajaran sistem komputer ini dengan baik, sebagai salah satu koleksi media pembelajaran yang dapat dimanfaatkan oleh guru dan siswa. (4) Kepada peneliti lain, saran untuk peneliti lain adalah karena pada media pembelajaran ini masih ada kekurangan baik dari segi desain ataupun kurangnya ilustrasi dalam bentuk gambar pada materi dalam media pembelajaran berbasis multimedia interaktif autoplay, nantinya agar menambahkan kekurangan pada media pembelajaran ini yang peneliti sekarang belum bisa untuk mengembangkan karena keterbatasan waktu.

\section{Daftar Pustaka}

Arsyad, Azhar.2014. Media pembelajaran. Jakarta:PT Raja Grafindo Persada

Darmiati, Ni Komang Eni, 2019. Pengembangan Video Animasi 3d Dalam Materi Pemasangan Instalasi Listrik Penerangan Rumah Pada Mata Pelajaran Keterampilan di SMP Negeri 6 Singaraja. Jurusan Teknologi Industri. Prodi S1 Pendidikan Teknik Elektro, Fakultas Teknik dan Kejuruan. Universitas Pendidikan Ganesha.

Dewi, Ni Luh Pramita, 2018. Pengembangan Media Pembelajaran Berbasis Multimedia Interaktif Autoplay Untuk Materi Pengenalan Komponen Elektronika Pada Siswa Kelas X TAV di SMK Negeri 3 Singaraja. Jurusan Pendidikan Teknik Elektro. Universitas Pendidikan Ganesha. 
Herlambang, Made Dony .2018. Pengembangan Simulasi Pembangkit Listrik Energi Terbarukan Sebagai Media Pembelajaran Prakarya dan Kewirausahaan Kelas XI MIA SMA N 4 Singaraja. Fakultas Teknik dan Kejuruan, Universitas Pendidikan Ganesha.

Hujair, Sanakiah. 2013. Media Pembelajaran Interaktif-Inovatif. Yogyakarta: Kaukaba Dipantara.

Laksana Wijaya .2019. Pengembangan Media Interaktif Tes Formatif Pada Mata Pelajaran Produktif Jurusan TKJ di SMK Negeri 3 Singaraja. Jurusan Teknologi Industri. Prodi S1 Pendidikan Teknik Elektro, Fakultas Teknik dan Kejuruan. Universitas Pendidikan Ganesha.

Musfiqon, 2012. Pengembangan Media dan Sumber Pembelajaran. Jakarta: PT Prestasi Pustakaraya.

Narimawati, Umi. 2007. Riset Manajemen Sumber Daya Manusia. Jakarta: Agung Media.

Pratama, I Gede Eka Yoga. 2018. Pengembangan Media Pembelajaran CD Interaktif Pada Mata Pelajaran Gambar Teknik Kelas X Titl Di Smk Negeri 3 Singaraja. Fakultas Teknik dan Kejuruan, Universitas Pendidikan Ganesha.

Sugiyono. 2015. Metode Penelitian Kombinasi (Mixed Methods). Bandung: Yogyakarta: media akademi dan R\&D). Bandung : Alfabeta.

Yasa, Kadek Aditya Pradipta. 2017. Pengembangan Media pembelajaran Interaktif Berbasis Adobe Flash pada Mata Pelajaran Prakarya dan Kewirausahaan Materi Elektro(Listrik) untuk Siswa Kelas XI MIPA dan IPS di SMA Negeri 3 Singaraja. Fakultas Teknik dan Kejuruan, Universitas Pendidikan Ganesha.

Undang-undang. 2003. Undang-Undang Republik Indonesia Nomor 20 Tahun 2003 Tentang Sistem Pendidikan Nasional. Jakarta: Sekretaris Negara Republik Indonesia. 